\title{
Inhibition of Acetylcholine Release from Guinea Pig Myenteric Neurons by Neuropeptide Y: GTP-Binding Protein Mediation ${ }^{1}$
}

\author{
Michael W. Mulholland and Salim Jaffer \\ Department of Surgery, University of Michigan, Ann Arbor, Michigan 48109-0331
}

Presented at the Annual Meeting of the Association for Academic Surgery, Houston, Texas, November 14-17, 1990

\begin{abstract}
Neuropeptide Y (NPY) is a unique peptide with wide distribution in central and peripheral nervous systems. In the guinea pig, NPY-positive fibers are prominent in the myenteric plexus. To test whether NPY inhibits myenteric plexus acetylcholine (ACh) release and to define mechanisms, a purified preparation of myenteric plexus neurons was derived from the teniae coli of neonatal guinea pigs and maintained in primary culture. Incubation of cultured neurons labeled with $\left[{ }^{3} \mathrm{H}\right] \mathrm{ACh}$ in the presence of NPY $\left(10^{-14}-10^{-6} M\right)$ significantly inhibited basal $\mathrm{ACh}$ release $(83 \pm 16$ to $58 \pm 11 \%$ of control). NPY significantly inhibited $\mathrm{ACh}$ release stimulated by potassium ( $55 \mathrm{mM}$ ); by adenylate cyclase agonists forskolin $\left(10^{-6} M\right)$ and cholera toxin $\left(10^{-8} M\right)$; and by calcitonin gene-related peptide, cholecystokinin octapeptide, and vasoactive intestinal peptide (each $\left.10^{-8} M\right)$. In each instance, the inhibitory effects of NPY were reversed hy preincubation with pertussis toxin. Reversal of inhibitory effects by pertussis toxin suggests that the actions of NPY are mediated via an inhibitory GTPbinding protein. (c) 1991 Academic Press, Inc.
\end{abstract}

\section{INTRODUCTION}

Neuropeptide Y (NPY) is a unique 37 amino acid peptide that was first isolated from the porcine brain [1]. The peptide, with expression restricted to neurons, is widely distributed in both the central and peripheral nervous systems [2-4]. NPY has strong amino acid sequence homology with pancreatic polypeptide (PP) and peptide YY (PYY); the three compose a family of regulatory peptides $[5,6]$. Pancreatic polypeptide immunoreactivity is found in endocrine cells of the pancreatic islets [7]. PYY immunoreactive cells have been localized within the mucosa of the gastrointestinal tract, especially the distal small intestine [8]. Within the digestive tract, NPY-positive neurons are found in the stomach, the intestine, and both the endocrine and exocrine portions of the pancreas $[9,10]$.

\footnotetext{
${ }^{1}$ This study was supported by National Institutes of Health Grant DK 40633.
}

In the guinea pig intestine, NPY-positive nerve fibers constitute approximately $5 \%$ of all neurons within the myenteric plexus (11). The gut contains both extrinsically and intrinsically derived NPY-positive neurons; extrinsic NPY nerve fibers have been reported to contain adrenergic neurotransmitters, the majority originating from postganglionic sympathetic neurons $[12,13]$. However, denervation experiments in rats indicate the largest number of the NPY-positive fibers are intramural in origin [14]. Intrinsic NPY-immunoreactive nerve fibers are believed to be nonadrenergic [13]. Intrinsic NPY-positive myenteric plexus neurons also stain positively for vasoactive intestinal polypeptide and peptide histidine isoleucine (PHI) $[15,16]$. This combination of anatomic findings suggests that NPY may have important actions on enteric neuronal activity.

Garzon and associates have reported that NPY reduces the resting tension of guinea pig longitudinal muscle strips [17]. NPY was also noted to reduce the excitatory effects of cholecystokinin octapeptide via a neurally mediated mechanism [17]. Close arterial infusion of NPY in the cat produces inhibition of colonic motility; the effect is not mediated by adrenergic receptors [18]. While the physiologic relevance of these actions of NPY within the myenteric plexus remains to be established, they suggest that the peptide may exert inhibitory actions upon enteric ncurons.

The current investigation was performed to test the hypothesis that NPY inhibits release of acetylcholine from enteric neurons and to study the mechanism by which such an inhibitory action might be exerted. The studies were designed to directly test the ability of NPY to modulate acetylcholine release by using cultured myenteric plexus neurons. The involvement of neuronal adenylate cyclase in the activity of NPY was determined and the potential role of GTP-binding proteins in the observed effects was examined.

\section{MATERIALS AND METHODS}

Materials. The following chemicals were purchased: hemicholinium, collagenase, penicillin, streptomycin, veratridine, forskolin, 8-bromo cyclic AMP, cholera 
toxin, pertussis toxin, poly-L-lysine (Sigma Chemical, St. Louis, MO), vasoactive intestinal peptide (VIP), substance $\mathrm{P}$, calcitonin gene-related peptide (CGRP), cholecystokinin octapeptide (CCK-8) (Peninsula Labs, Belmont, CA), Medium 199, (GIBCO, Grand Island, $\mathrm{NY}$ ), and Nu-Serum (Collaborative Research, Bedford, MA). Neonatal Duncan-Hartley guinea pigs were purchased from Simonsen Labs (Gilroy, CA). Tritiated choline and tritiated acetylcholine were obtained from New England Nuclear (Boston, MA).

Myenteric plexus neuronal culture. Primary culture of myenteric plexus neurons was accomplished by an adaptation of previously described methods $[19,20]$. Neonatal Duncan-Hartley guinea pigs were sacrificed, and using aseptic technique, the longitudinal smooth muscle of the teniae coli was dissected from the cecum; care was exercised not to enter the lumen of the bowel. Teniae coli were divided into 5 - to $6-\mathrm{mm}$ segments and were transferred to a Petri dish containing Hanks' balanced salt solution (HBSS) with highly purified collagenase $(1 \mathrm{mg} / \mathrm{ml})$ and incubated at $37^{\circ} \mathrm{C}$ for $1.25-1.5 \mathrm{hr}$. Tissue fragments were then transferred to fresh HBSS where, under a dissecting microscope, loosely adherent smooth muscle cells were dissected from the myenteric plexus, producing a purified myenteric plexus preparation [21]. Cell viability was maintained up to 21 days in culture.

The tissues derived from each animal were divided into 12 segments (approximately $10^{5}$ cells per segment). Isolated plexuses were explanted into tissue culture wells previously coated with poly-L-lysine $(10 \mu \mathrm{g} / \mathrm{ml})$. Plexuses were exposed to culture medium containing Medium 199 supplemented with nonessential amino acids, Na-pyruvate, Hepes buffer $(1 M)$, and L-glutamate $(200 \mathrm{mM})$ plus NU-Serum (10\%), glucose $(5 \mathrm{mg} /$ $\mathrm{ml})$, and penicillin-streptomycin solution $(100 \mathrm{U} / \mathrm{ml})$. Culture medium was exchanged every second day and antibiotics were omitted after the initial feeding. Acetylcholine release studies were performed after 5 to 7 days in culture. Cultured plexuses were used for study only if they were firmly adherent to the culture well and exhibited extensive outgrowth of dendritic processes. Each plexus culture was inspected for the presence of uniform neuronal growth.

Acetylcholine release studies. The release of $\left[{ }^{3} \mathrm{H}\right]-$ labeled acetylcholine $\left(\left[{ }^{3} \mathrm{H}\right] \mathrm{ACh}\right)$ was studied after exposure of neurons to $\left[{ }^{3} \mathrm{H}\right]$ choline $(0.2 \mu \mathrm{M}$, specific activity $80 \mathrm{Ci} / \mathrm{mmole}$ ) in oxygenated modified Krebs-Ringer buffer containing $50 \mu M$ physostigmine. Incubation with $\left[{ }^{3} \mathrm{H}\right]$ choline was carried out at $37^{\circ} \mathrm{C}$ for $60 \mathrm{~min}$ in a Dubnoff metabolic incubator gassed with $95 \% \mathrm{O}_{2}-5 \% \mathrm{CO}_{2}$. Tissues were then washed twice with fresh buffer and allowed to recover for $30 \mathrm{~min}$ before exposure to agonists.

Each neuronal aggregate was exposed to only one test condition. Plexuses were exposed to NPY for $30 \mathrm{~min}$ before addition of agonists in those experiments utilizing coincubation with a test peptide. In experiments employing pertussis toxin, neurons were coincubated with the toxin for $18 \mathrm{hr}$ prior to addition of agonists.

In all experiments, total ${ }^{3} \mathrm{H}$ was determined to indicate transmitter release. Labeled neurons were washed and then exposed to agonists in a release medium containing the following constituents: $\mathrm{NaCl}, 118 \mathrm{mM} ; \mathrm{KCl}$, $4.7 \mathrm{mM} ; \mathrm{NaHPO}_{4}, 1 \mathrm{mM} ; \mathrm{MgCl}_{2}, 0.5 \mathrm{mM} ; \mathrm{CaCl}_{2}, 2.5$ $\mathrm{mM} ; \mathrm{NaHCO}_{3}, 25 \mathrm{mM}$; glucose, $11.1 \mathrm{mM}$; physostigmine, $50 \mu M$ and hemicholinium, $10 \mu M$. NaCl was adjusted to maintain osmolarity. Labeled neurons were exposed to agonists in this release medium for $15 \mathrm{~min}$; the release medium was then aspirated and added to scintillation fluid. The remaining tissue was solubilized and then placed in scintillation fluid. Radioactivity was quantified by liquid scintillation spectrometry. $\left[{ }^{3} \mathrm{H}\right] \mathrm{ACh}$ was expressed as the percentage of total tissue ${ }^{3} \mathrm{H}$ released into the medium.

In order to verify that the ${ }^{3} \mathrm{H}$ released was $\mathrm{ACh}$, column chromatography was used. After stimulation with the respective agonists, aliquots of release medium were applied to a cation exchange resin (Bio-Rex 70) to separate $\left[{ }^{3} \mathrm{H}\right] \mathrm{ACh}$ and $\left[{ }^{3} \mathrm{H}\right]$ choline from other products. Unlabeled ACh and choline were applied to the column along with $\left[{ }^{14} \mathrm{C}\right] \mathrm{ACh}$ as a marker for $\mathrm{ACh}$. The column was eluted with $\mathrm{NaHPO}_{4}$ buffer and radioactivity was determined. Two peaks of radioactivity were observed and greater than $90 \%$ of the increase in ${ }^{3} \mathrm{H}$ occurring after stimulation was in the form of $\left[{ }^{3} \mathrm{H}\right] \mathrm{ACh}$.

Data analysis. Fractional release was calculated by expressing the radioactivity in the release medium as the percentage of total radioactivity in the tissue at the time of the experiment. The percent release of $\left[{ }^{3} \mathrm{H}\right] \mathrm{ACh}$ over basal was calculating by dividing the fractional release produced by agonists by the spontaneous (basal) release. All results were expressed as group means \pm SEM. Each experiment was performed using the tissues derived from one animal; the sample size ( $n$ value) was taken as the number of guinea pigs; all experimental groups had $n$ values of 6 to 8 . Statistical analysis was performed using one-way analysis of variance. Significance was accepted as $P<0.05$.

\section{RESULTS}

Effects of NPY on basal ACh release. To determine if NPY inhibits basal ACh release from cultured myenteric plexus neurons, we examined the effects of the peptide on $\left[{ }^{3} \mathrm{H}\right] \mathrm{ACh}$ release from unstimulated neuronal plexuses. Neurons were exposed to varying concentration of NPY for $15 \mathrm{~min}$ in release medium to which no agonists had been added. Mean 15-min basal release was $4.5 \pm 0.2 \%$ in the absence of NPY. Basal release of $\left[{ }^{3} \mathrm{H}\right] \mathrm{ACh}$ was significantly suppressed $(68 \pm 10 \%$ of control) by exposure of plexuses to NPY at concentrations 


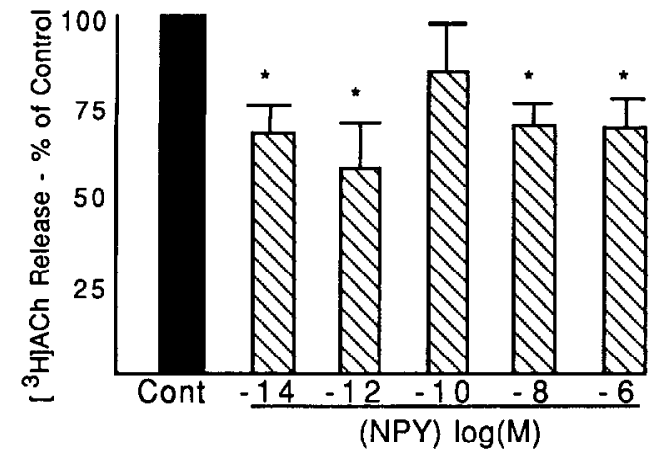

FIG. 1. Effect of NPY on basal $\left[{ }^{3} \mathrm{H}\right] \mathrm{ACh}$ release from cultured myenteric plexus neurons. $\left[{ }^{3} \mathrm{H}\right] \mathrm{ACh}$-labeled neurons ( $n-6$ animals) were exposed to release medium in the absence or presence of graded concentrations of NPY for $15 \mathrm{~min}$. $\left[{ }^{3} \mathrm{H}\right] \mathrm{ACh}$ release was quantified as the percentage released into the medium relative to the total contained within the tissue at the beginning of the experiment. ${ }^{*} P<0.05$ vs control.

as low as $10^{-14} M$ (Fig. 1). Statistically significant inhibitory effects were observed at each of the NPY concentrations employed except $10^{-10} M$.

Effects of NPY on stimulated ACh release. Preliminary studies were performed to determine responsiveness of cultured neurons in terms of $\left[{ }^{3} \mathrm{H}\right] \mathrm{ACh}$ release to various agonists. Exposure to potassium $(55 \mathrm{mM})$ caused significant increases in $\left[{ }^{3} \mathrm{H}\right] \mathrm{ACh}$ release $(261 \pm$ $47 \%$ of basal). Dose-dependent increases in $\left[{ }^{3} \mathrm{H}\right] \mathrm{ACh}$ release were noted with exposure to the depolarizing agent veratridine, with maximal stimulation noted at $10^{-6} \mathrm{M}$ $(342 \pm 67 \%)$. Incubation with the cyclic AMP agonists forskolin, cholera toxin (CTX), or 8-bromo cyclic AMP was, in each instance, associated with dose-related increases in labeled ACh release. Exposure to peptide neurotransmitters was also associated with dose-related increases in $\left[{ }^{3} \mathrm{H}\right] \mathrm{ACh}$ release. Incubation with CGRP or CCK-8 $(10 \mathrm{~nm})$ produced increases in $\left[{ }^{3} \mathrm{H}\right] \mathrm{ACh}$ release of $73 \pm 33 \%$ and $82 \pm 28 \%$ above basal values, respectively. Substance $P$ exposure dose-dependently increased $\left[{ }^{3} \mathrm{H}\right] \mathrm{ACh}$ release $(179 \pm 62 \%$ at $10 \mathrm{~nm})$, as did VIP (10 $\mathrm{nm}$ incubation: $227 \pm 49 \%$ of basal). Dose-response data were used to calculate $\mathrm{ED}_{50}$ values for each agonist. Submaximal agonist concentrations, for use in subsequent combination with NPY, were chosen based upon these agonist dose-response studies.

To investigate potential inhibitory effects of NPY on stimulated ACh release, we coincubated NPY with the above agonists. In experiments using NPY, the peptide $\left(10^{-8} M\right)$ was added to the release medium 15 min before exposure to agonist. To investigate the possibility that NPY antagonizes stimulated ACh release via activation of inhibitory $\left(G_{i}\right)$ regulatory proteins, in some experiments we exposed neurons to pertussis toxin (PTX) prior to addition of NPY and agonists. Pertussis toxin has been demonstrated to ribosylate the $G_{i}$ protein and thereby to block the inhibitory actions of agents utiliz-

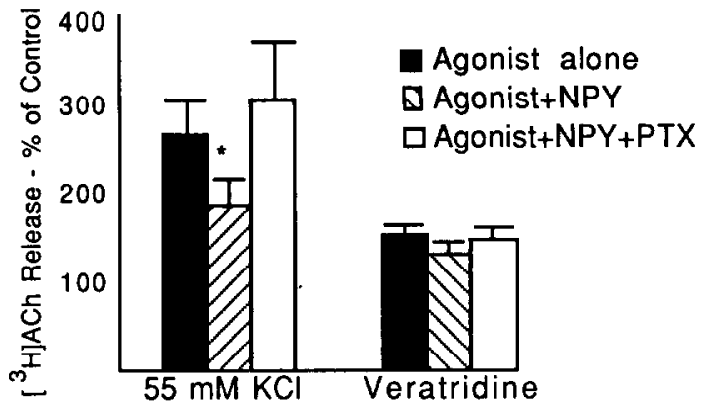

FIG. 2. Effects of NPY on potassium and veratridine-stimulated $\left[{ }^{3} \mathrm{H}\right] \mathrm{ACh}$ release. Labeled neurons were exposed to potassium (55 $\mathrm{m} M)$ or to veratridine $\left(10^{-8} M\right)$ in release medium. NPY $\left(10^{-8} M\right)$ was added 15 min prior to exposure to agonists. In experiments utilizing PTX ( $100 \mathrm{ng} / \mathrm{ml})$, toxin was added to culture medium $18 \mathrm{hr}$ prior to exposure to agonists. ${ }^{*} P<0.05$ vs control.

ing this mechanism. Pertussis toxin $(100 \mathrm{ng} / \mathrm{ml})$ was added $18 \mathrm{hr}$ prior to $\left[{ }^{3} \mathrm{H}\right]$ choline exposure.

NPY produced significant suppression of potassiumstimulated $\left[{ }^{3} \mathrm{H}\right] \mathrm{ACh}$ release $(190 \pm 36 \%$ of basal) (Fig. 2 ). The inhibitory effects of NPY on potassium-stimulated $\left[{ }^{3} \mathrm{H}\right] \mathrm{ACh}$ release were reversed by preincubation with PTX $(304 \pm 71 \%)$. Veratridine-stimulated $\left(10^{-8} M\right)$ $\left[{ }^{3} \mathrm{H}\right] \mathrm{ACh}$ was modestly decreased after exposure to NPY (from $144 \pm 5 \%$ to $119 \pm 10 \%$ ); the difference did not achieve statistical significance, however (Fig. 2).

$\left[{ }^{3} \mathrm{H}\right] \mathrm{ACh}$ release stimulated by forskolin $\left(10^{6} \mathrm{M}\right)$ was abolished by preincubation with NPY ( $260 \pm 79 \%$ vs 84 $\pm 14 \%)$. The inhibitory effects of NPY were reversed by PTX pretreatment (Fig. 3). Similarly, NPY inhibited ACh release stimulated by CTX, decreasing fractional [ $\left.{ }^{3} \mathrm{H}\right] \mathrm{ACh}$ release from $212 \pm 52 \%$ to $72 \pm 10 \%$ of basal. PTX pretreatment reversed NPY inhibition of CTX effects $(152 \pm 12 \%)$. In contrast to the effects observed with forskolin or CTX, stimulation of $\left[{ }^{3} \mathrm{H}\right] \mathrm{ACh}$ release by 8-bromo cyclic AMP was not affected by NPY (Fig. 3).

In the last group of experiments, the ability of NPY to inhibit neuropeptide-stimulated ACh release was tested

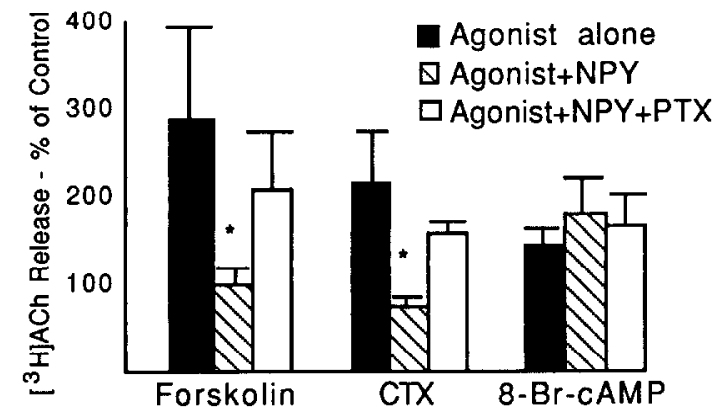

FIG. 3. Effects of NPY on $\left[{ }^{3} \mathrm{H}\right] \mathrm{ACh}$ release stimulated by cAMP agonists. Labeled plexuses were stimulated by forskolin $\left(10^{-6} M\right)$, cholera toxin (CTX: $10^{-8} M$ ), or 8-bromo cyclic AMP $\left(10^{-8} M\right)$. In accompanying wells, neurons were exposed to agonist plus NPY $\left(10^{-8} M\right)$ or to NPY after preincubation with PTX. ${ }^{*} P<0.05$ vs control. 


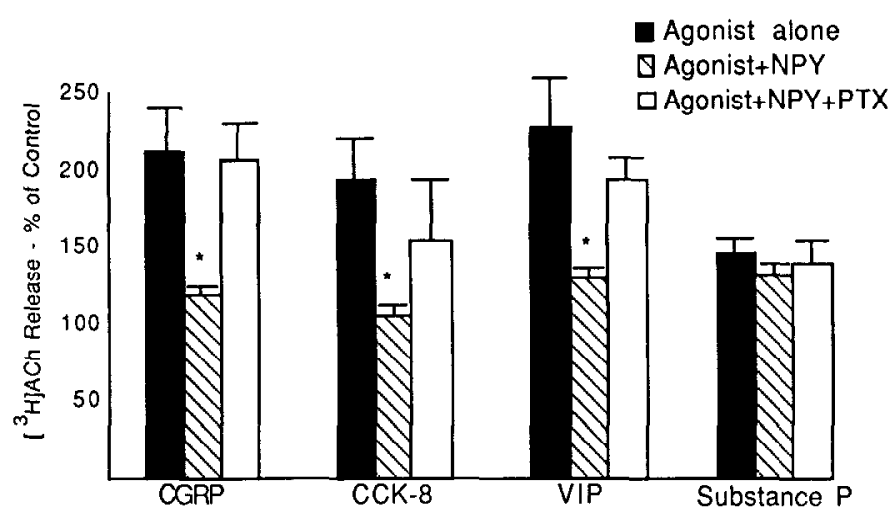

FIG. 4. Effects of NPY on neuropeptide-stimulated $\left[{ }^{3} \mathrm{H}\right] \mathrm{ACh}$ release. Cultured neurons were exposed to CGRP, CCK-8, VIP, or substance $P\left(10^{-8} \mathrm{M}\right)$ alone, or with NPY $\left(10^{-8} M\right)$, or with NPY after PTX preincubation $(n=8),{ }^{*} P<0.05$ vs control.

(Fig. 4). NPY significantly inhibited CGRP-stimulated $\left[{ }^{3} \mathrm{H}\right] \mathrm{ACh}$ release $(209 \pm 31 \%$ vs $120 \pm 9 \%)$; the inhibitory effects were reversed by PTX preexposure $(205 \pm 29 \%)$. CCK-8-stimulated ACh release ( $192 \pm 28 \%$ of basal) was significantly diminished by NPY coincubation (110 $\pm 13 \%$ ); PTX preincubation reversed the inhibitory effects. Similarly, VIP stimulation of $\left[{ }^{3} \mathrm{H}\right] \mathrm{ACh}$ release was suppressed by NPY exposure ( $227 \pm 49 \%$ vs $130 \pm 12 \%)$, and the inhibitory effects were reversible with PTX pretreatment. In contrast, $\left[{ }^{3} \mathrm{H}\right] \mathrm{ACh}$ release stimulated by substance $P$ was not inhibited by NPY coincubation.

\section{DISCUSSION}

This study has clearly demonstrated that NPY inhibits the release of ACh from cultured guinea pig myenteric plexus neurons. NPY was observed to suppress basal release of $\left[{ }^{3} \mathrm{H}\right] \mathrm{ACh}$ at concentrations as low as $10^{-14}$ $M$, indicating both its potent inhibitory effects and the sensitivity of the neurons in culture to respond to exogenous peptides. NPY was also noted to inhibit $\left[{ }^{3} \mathrm{H}\right] \mathrm{ACh}$ release stimulated by potassium-induced depolarization and by a variety of cholinergic secretagogues.

In preliminary studies, forskolin, cholera toxin, and 8-bromo cyclic AMP were each shown to stimulate $\left[{ }^{3} \mathrm{H}\right] \mathrm{ACh}$ release from myenteric plexus neurons, confirming previous reports that agents which raise intracellular cAMP levels stimulate the release of $\mathrm{ACh}$ from the myenteric plexus [22]. NPY was observed to inhibit the effects of forskolin, an agent which stimulates adenylate cyclase activity and the effects of CTX, an agent that activates adenylate cyclase indirectly through effects on stimulatory GTP-binding proteins $[23,24]$. In contrast, $\left[{ }^{3} \mathrm{H}\right] \mathrm{ACh}$ release stimulated by 8 -bromo cAMP, a soluble congener of cAMP, was not affected by NPY exposure. The ability of 8-bromo cAMP to mimic increased intracellular cAMP levels does not depend upon activation of adenylate cyclase. These observa- tions, taken together, suggest that NPY inhibits cholinergic transmission in the myenteric plexus by inhibiting neuronal adenylate cyclase and preventing accumulation of intracellular cAMP. In support of this mechanism, NPY has recently been reported to inhibit forskolin-stimulated cAMP accumulation in the nucleus tractus solitarius region of the rat brain [25].

NPY was also demonstrated to inhibit $\mathrm{ACh}$ release stimulated by CGRP, CCK-8, or by VIP; the magnitude of the inhibitory effects were similar (approximately $45 \%$ ) for each of the peptide agonists. Recent reports provide indirect evidence that intracellular cAMP accumulation may mediate $\mathrm{ACh}$ release from myenteric neurons caused by each of these peptides. CGRP has been reported to stimulate $A C h$ release from myenteric plexus neurons. The release occurs via a mechanism that is sensitive to 2 ',5'-dideoxyadenosine [26]. Dideoxyadenosine has been shown to inhibit neuronal adenylate cyclase and to block the accumulation of intracellular cAMP. The ability of VIP to increase ACh release from myenteric plexus neurons is also sensitive to dideoxyadenosine, indicating activity via neuronal adenylate cyclase [27]. In addition, electrophysiological studies using myenteric plexus neurons have demonstrated that VIP and CCK-8 generate slow excitatory postsynaptic potentials, a pattern characteristically associated with cholinergic depolarization [28, 29]. The generation of slow excitatory postsynaptic potentials can be blocked by adenosine. The ability of NPY to inhibit $\left[{ }^{3} \mathrm{H}\right] \mathrm{ACh}$ release stimulated by CGRP, CCK-8, or VIP demonstrated in the current investigations is thus consistent with a mechanism involving inhibition of adenylate cyclase. In contrast, NPY was not noted to inhibit $\left[{ }^{3} \mathrm{H}\right] \mathrm{ACh}$ release stimulated by substance $\mathrm{P}$. The effects of substance $P$ are not mediated, in myenteric plexus neurons, via effects on intracellular cAMP.

The inhibitory actions of NPY on $\left[{ }^{3} \mathrm{H}\right] \mathrm{ACh}$ release were pertussis toxin sensitive. Guanine nucleotide-binding proteins have been demonstrated in a number of systems that couple inhibitory receptors to membranebound adenylate cyclase [30]. Such regulatory components $\left(G_{i}\right)$ are sensitive to ADP-ribosylation catalyzed by pertussis toxin; exposure to pertussis toxin inactivates $G_{i}$ and prevents inhibitory peptides from decreasing adenylate cyclase activity. The reversal of NPY inhibition of forskolin- and CTX-stimulated $\left[{ }^{3} \mathrm{H}\right] \mathrm{ACh}$ release by PTX pretreatment strongly suggests G protein involvement in the observed actions. PTX sensitivity of NPY inhibition of $\mathrm{ACh}$ release stimulated by CGRP, CCK-8, and VIP provides further support for the involvement of $G_{i}$ protein in the actions of NPY in myenteric plexus neurons. Wiley and co-workers have demonstrated that an inhibitory guanine nucleotide-binding protein mediates NPY inhibition of ACh release from nodose ganglion neurons [31]. Additionally, in myenteric plexus neurons, inhibition of ACh release by somatostatin has also been shown to be PTX-sensitive 
[22]. G protein mediation of adenylate cyclase activity, demonstrated in this study for NPY, may serve as a mechanism by which a variety of inhibitory neurotransmitters or hormones regulate cholinergic transmission within the myenteric plexus.

\section{REFERENCES}

1. Tatemoto, K., Carlquist, M., and Mutt, V. Neuropeptide Y-A novel brain peptide with structural similarities to peptide $Y Y$ and pancreatic polypeptide. Nature 296: 659, 1982.

2. DiMaggio, D. A., Chronwall, B. M., Buchanan, K., and O'Donohue, T. L. Pancreatic polypeptide immunoreactivity in rat brain is actually neuropeptide Y. Neuroscience 15: 1149, 1985.

3. Allen, J. M., Gjorstrup, P., Bjorkman, J.-A., Ek, L., Abrahamsson, T., and Bloom, S. R. Studies on cardiac distribution and function of neuropeptide Y. Acta Physiol. Scand. 126: 405, 1986.

4. Polak, J. M., and Bloom, S. R. Regulatory peptides-The distribution of two newly discovered peptides: PHI and NPY. Peptides 5(Suppl. I): 79, 1984.

5. Schwartz, T. W., and Tager, H. S. Isolation and biogenesis of a new peptide from pancreatic islets. Nature 294: 589, 1981.

6. Tatemoto, K. Isolation and characterization of peptide YY (PYY), a candidate gut hormone that inhibits pancreatic exocrine secretion. Proc. Natl. Acad. Sci. USA 79: 2514, 1982.

7. Larsson, L. I., Sundler, F., and Hakanson, R. Immunohistochemical localization of human pancreatic polypeptide (HPP) to a population of islet cells. Cell Tissue Res. 156: 167, 1975.

8. Lundberg, J. M., Tatemoto, K., Terenius, L., Hellstrom, P. M., Mutt, V., and Hokfelt, T. Localization of peptide YY (PYY) in gastrointestinal endocrine cells and effects on intestinal blood flow and motility. Proc. Natl. Acad. Sci. USA 79: 4471, 1982.

9. Carlei, F., Allen, J. M., Bishop, A. E., Bloom, S. R., and Polak, J. M. Occurrence, distribution and nature of neuropeptide $\mathrm{Y}$ in the rat pancreas. Experientia 41: 1554, 1985.

10. Pettersson, M., Ahren, B., Lundquist, I., Bottcher, G., and Sundler, F. Neuropeptide Y: Intrapancreatic neuronal localization and effects on insulin secretion in the mouse. Cell Tissue Res, 248: 43, 1987.

11. Furness, J. B., Costa, M., and Emson, P. C. Distribution, pathways and reactions to drug treatment of nerves with neuropeptide $\mathrm{Y}$ - and pancreatic polypeptide-like immunoreactivity in the guinea pig digestive tract. Cell Tissue Res. 234: 71, 1983.

12. Su, H. C., Bishop, A. E., Power, R. F., Hamada, Y., and Polak, J. M. Dual intrinsic and extrinsic origins of CGRP- and NPYimmunoreactive nerves of the rat gut and pancreas. J. Neurosci. 7: $2674,1987$.

13. Lindh, B. T., Hokfelt, T., Elfvin, L.-G., Terenius, L., Fahrenkrug, J., Elde, R., and Goldstein, M. Topography of NPY-, somatostatin-, and VIP immunoreactive neuronal subpopulations in the guinea pig celiac-superior mesenteric ganglion and their projection to the pylorus. J. Neurosci. 6: 2371, 1986.

14. Sundler, F., Moghimzadeh, E., Hakanson, R., Ekelund, M., and Emson, P. Nerve fibers in the gut and pancreas of the rat displaying neuropeptide-Y immunoreactivity. Cell Tissue Res. 230: 487, 1983.
15. Bornstein, J. C., Furness, J. B., and Costa, M. Sources of excitatory synaptic inputs into neurochemically identified submucous neurons of the guinea-pig small intestine. J. Auton. Nerv. Syst. 18: 83, 1987.

16. Ekblad, E., Hakanson, R., and Sundler, F. VIP and PHI coexist with an NPY-like peptide in intramural neurones of the small intestine. Regul. Pept. 10: 47, 1984.

17. Garzon, J., Hollt, V., and Sanchez-Blazquez, P. Neuropeptide Y is an inhibitor of neural function in the myenteric plexus of the guinea-pig ileum. Peptides 7: 623, 1986.

18. Hellstrom, P. M., Olerup, O., and Tatemoto, K. Neuropeptide $Y$ may mediate effects of sympathetic nerve stimulations on colonic motility and blood flow in the cat. Acta Physiol. Scand. 124: $613,1985$.

19. Jessen, K. R., Suffrey, M. J., and Burnstock, G. The enteric nervous system in tissue culture. $I$. Cell types and their interactions in explants on the myenteric and submucous plexuses from guinea pig, rabbit, and rat. Brain Res. 262: 17, 1983.

20. Saffrey, M. J., and Burnstock, G. Growth of myenteric plexus explant cultures in a serum-free, hormone-supplemented culture medium. Int. J. Dev. Neurosci. 2: 591, 1984.

21. Mulholland, M. W., and Jaffer, S. Stimulation of acetylcholine release in myenteric plexus by calcitonin gene-related peptide. Am. J. Physiol. 259: G934, 1990.

22. Wiley, J., and Owyang, C. Somatostatin inhibits cAMP-mediated cholinergic transmission in the myenteric plexus. $A \mathrm{~m}$. J. Physivl. 253: G607, 1987.

23. Seamon, K. B., and Daly, J. W. Forskolin: A unique diterpene activator of cyclic AMP generating system. J. Cyclic Nucleotide Res. 7: 201, 1981.

24. Sharp, G. W. G., and Hynie, S. Stimulation of intestinal adenyl cyclase by cholera toxin. Nature 229: 229, 1971.

25. Harfstrand, A., Fredholm, B., and Fuxe, K. Inhibitory effects of neuropeptide $Y$ on cyclic AMP accumulation in slices of the nucleus tractus solitarius region of the rat. Neurosci. Lett. 76: 185, 1987.

26. Snyder, S. H. Adenosine as a neuromodulator. Annu. Rev. Neurosci. 8: 103, 1985.

27. Zafirov, D. H., Palmer, J. M., Nemeth, P. R., and Wood, J. D. Bombesin, gastrin-releasing peptide and vasoactive intestinal peptide excite myenteric neurons. Eur. .J. Pharmacol. 115: 103, 1985.

28. Nemeth, P. R., Ort, C. A., Zafirov, D. H., and Wood, J. D. Cholecystokinin octapeptide and caerulin but not pentagastrin alter electrical behavior of myenteric neurons of guinea pig ileum. Dig. Dis. Sci. 29: 559, 1984

29. Palmer, J. M., Zafirov, D. H. Nemeth, P. R., and Wood, J. D. Peptidergic modulation of excitability in myenteric plexus neurons. Dig. Dis. Sci. 30: 786, 1985.

30. Casey, P. J., Graziano, M. P., Freissmuth, M., and Gilman, A. G. Role of $\mathrm{G}$ proteins in transmembrane signaling. Cold Spring Harb. Symp. Quant. Biol. 53: 203, 1988.

31. Wiley, J. W., Gross, R. A., and Macdonald, R. L. Neuropeptide Y inhibits acetylcholine release from vagal sensory (nodose) neurons via reduction of calcium current: Mediation by an inhibitory guanine nucleotide binding protein. Gastroenterology 96: A546, 1989. 